Brit. J. industr. Med., 1955, 12, 290.

\title{
THE ENERGY EXPENDED WHILE WALKING IN STOOPING POSTURES
}

\author{
BY \\ THOMAS BEDFORD and C. G. WARNER \\ From the Medical Research Council's Environmental Hygiene Research Unit, \\ London School of Hygiene and Tropical Medicine
}

(RECEIVED FOR PUBLICATION APRIL 1, 1955)

In mine roadways the roof is frequently so low that it is impossible to walk in the natural erect manner and it is necessary to stoop, sometimes to a considerable extent. Indeed, in a very low place it may be necessary to travel some distance on all fours. Walking in low roadways can be very fatiguing when a pronounced stoop is necessary, for the energy cost of walking in such a posture is greater than that incurred in walking in the usual erect posture at the same speed.

In a study of the energy output of coal-miners during work Moss (1935) made observations of the oxygen intake during walking in different postures along a level floor at a constant speed of $3 \frac{1}{2}$ miles per hour. His subjects were eight miners, all trained rescue men, who were accustomed to wearing a mouthpiece and nose-clip and were also used to low roadways. Experiments were made with the subjects walking in four postures : $(a)$ erect ; $(b)$ in a posture referred to as "half stoop", in which the subject stooped enough to reduce his height by about $20 \%$; (c) "full stoop ", in which the height was reduced by $40 \%$; and $(d)$ " all fours", in which the subject walked on hands and feet and reduced his height by about $50 \%$.

Moss concluded that the energy cost of walking at $3 \frac{1}{2}$ miles per hour in the half-stoop posture was about $20 \%$, in the full-stoop posture $66 \%$, and on all fours about $73 \%$ more than the cost of walking erect, and he remarked that the wastage of energy due to walking along low roadways must make an appreciable difference to a man's output of work at the coal face.

From the brief mention of the experimental technique given in Moss's paper it appeared that the energy cost with the greater reductions of height was underestimated. Three expiratory air samples of three-, two- or one-minute duration, according to the exacting nature of the work, were taken and averaged, and the average values of oxygen intake thus determined were taken as representing the energy output when walking in the various postures. No allowance appears to have been made for the large oxygen debt which is incurred during a short bout of such violent exercise as progressing on all fours at $3 \frac{1}{2}$ miles an hour.

Moss's results appeared to be of some practical significance, and soon after they were published we made a series of observations on ourselves in which we walked at various speeds and as nearly as possible in the postures described. In view of the attention now being devoted to the physiological problems of mining, it may be of some interest to report the results of those observations.

\section{Method of Experiment}

The experiments were carried out on the smooth wooden floor of a long corridor. Ordinary walking was done at rates of 2 to 5 miles an hour, half-stoop walking at 2 to 4 miles an hour, and in the full-stoop and all-fours postures the speeds ranged from 2 to $3 \frac{1}{2}$ miles an hour.

For the measurement of respiratory exchange the usual Douglas-Haldane technique was employed.

Preliminary experiments showed that in the erect and half-stoop postures a steady state was readily attained, and the results for these postures presented here were obtained under steady-state conditions. Owing to the severe nature of the exercise it was found impossible to continue full-stoop walking for more than a minute or a minute and a half, or walking on all fours for more than $\mathbf{4 0}$ to 50 seconds, so that in estimating the energy expenditure while walking in these postures the oxygen consumption during recovery had to be ascertained and allowance made for the heavy oxygen debt. With these very short spells of exercise the estimates of total oxygen usage may be subject to some error, but they do at any rate show the order of magnitude of the oxygen consumption. 


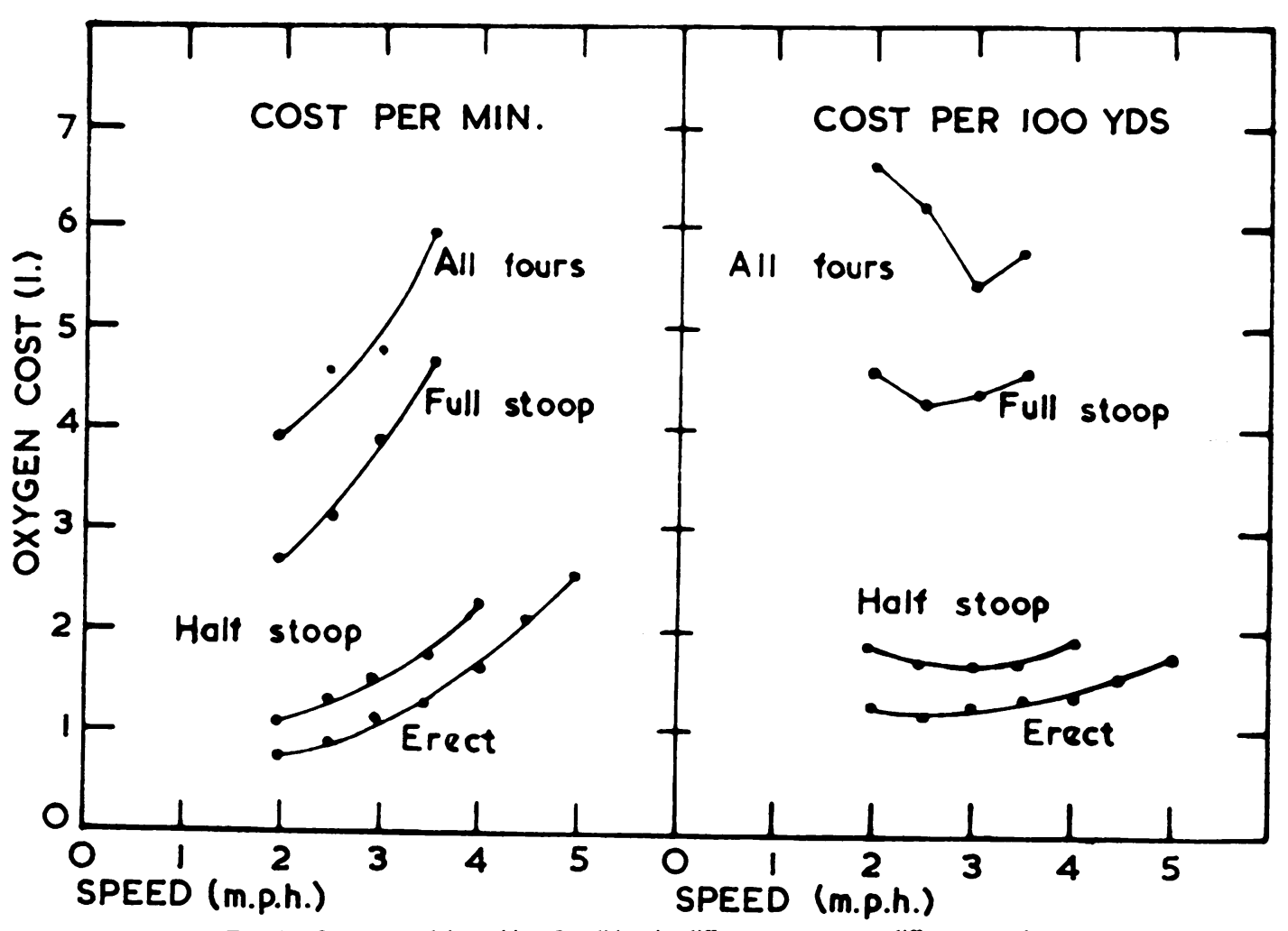

Fig. 1.-Oxygen used by subject I walking in different postures at different speeds.

The walking at various speeds was done by Subject I (aged 41 years, height 68 in., weight 144 lb.), and further experiments at $3 \frac{1}{2}$ miles an hour were done by Subject II (aged 33 years, height 65 in., weight 142 lb.). Neither subject was in athletic training, but a few years previously both had had much experience in traversing low mine roadways.

\section{Experimental Results}

The oxygen used by Subject I while walking at different speeds and in different postures is shown in Fig. 1, and the cost of walking in the various postures relative to that of walking erect at the same

TABLE 1

OXYGEN REQUIREMENT OF SUBJECT I WHEN WALKING WITH A STOOP AND ON ALL FOURS

\begin{tabular}{|c|c|c|c|c|}
\hline \multirow{2}{*}{$\begin{array}{l}\text { Speed } \\
\text { (miles per } \\
\text { hour) }\end{array}$} & \multirow{2}{*}{$\begin{array}{l}\text { Oxygen } \\
\text { Require- } \\
\text { ment for } \\
\text { Normal } \\
\text { Walking } \\
\text { (1. per min.) }\end{array}$} & \multicolumn{3}{|c|}{$\begin{array}{l}\text { Oxygen Requirement (as percentage } \\
\text { of that of normal walking) when } \\
\text { Walking }\end{array}$} \\
\hline & & $\begin{array}{c}\text { With } \\
\text { Half Stoop }\end{array}$ & $\begin{array}{c}\text { With } \\
\text { Full Stoop }\end{array}$ & $\begin{array}{l}\text { On } \\
\text { All Fours }\end{array}$ \\
\hline $\begin{array}{l}2 \\
2 \frac{1}{2} \\
3 \\
3 \frac{1}{2} \\
4\end{array}$ & $\begin{array}{l}0.74 \\
0.88 \\
1 \cdot 12 \\
1.34 \\
1.63\end{array}$ & $\begin{array}{l}149 \\
143 \\
132 \\
131 \\
138\end{array}$ & $\begin{array}{c}364 \\
356 \\
345 \\
349 \\
-\end{array}$ & $\begin{array}{l}526 \\
520 \\
427 \\
442 \\
-\end{array}$ \\
\hline
\end{tabular}

speed is shown in Table I. At any given speed the cost of walking with a stoop was distinctly greater than that of walking erect. With a height reduction of $20 \%$ (half stoop) the cost was 31 to $49 \%$ greater ; with a reduction of $40 \%$ (full stoop) the cost was about three and a half times that of walking erect ; while the cost of progression on all fours was four or five times that of normal walking. At $3 \frac{1}{2}$ miles an hour on all fours the oxygen cost was in the neighbourhood of 6 litres a minute.

Experiments in which Subject II walked at $3 \frac{1}{2}$ miles an hour, the speed used by Moss, gave similar results. Fig. 2 shows that the oxygen costs of the two subjects were almost identical.

Walking in the full-stoop posture or on all fours, especially at $3 \frac{1}{2}$ miles an hour, was very strenuous, and although the exertion could be continued by us for only about one minute an oxygen debt of up to $3 \frac{1}{2}$ litres was incurred. This is illustrated by the results of an experiment in which Subject II walked in the full-stoop posture for one minute after previously reclining in an armchair.

In this experiment the oxygen requirement of walking for one minute was $5 \cdot 2$ litres, of which 1.73 


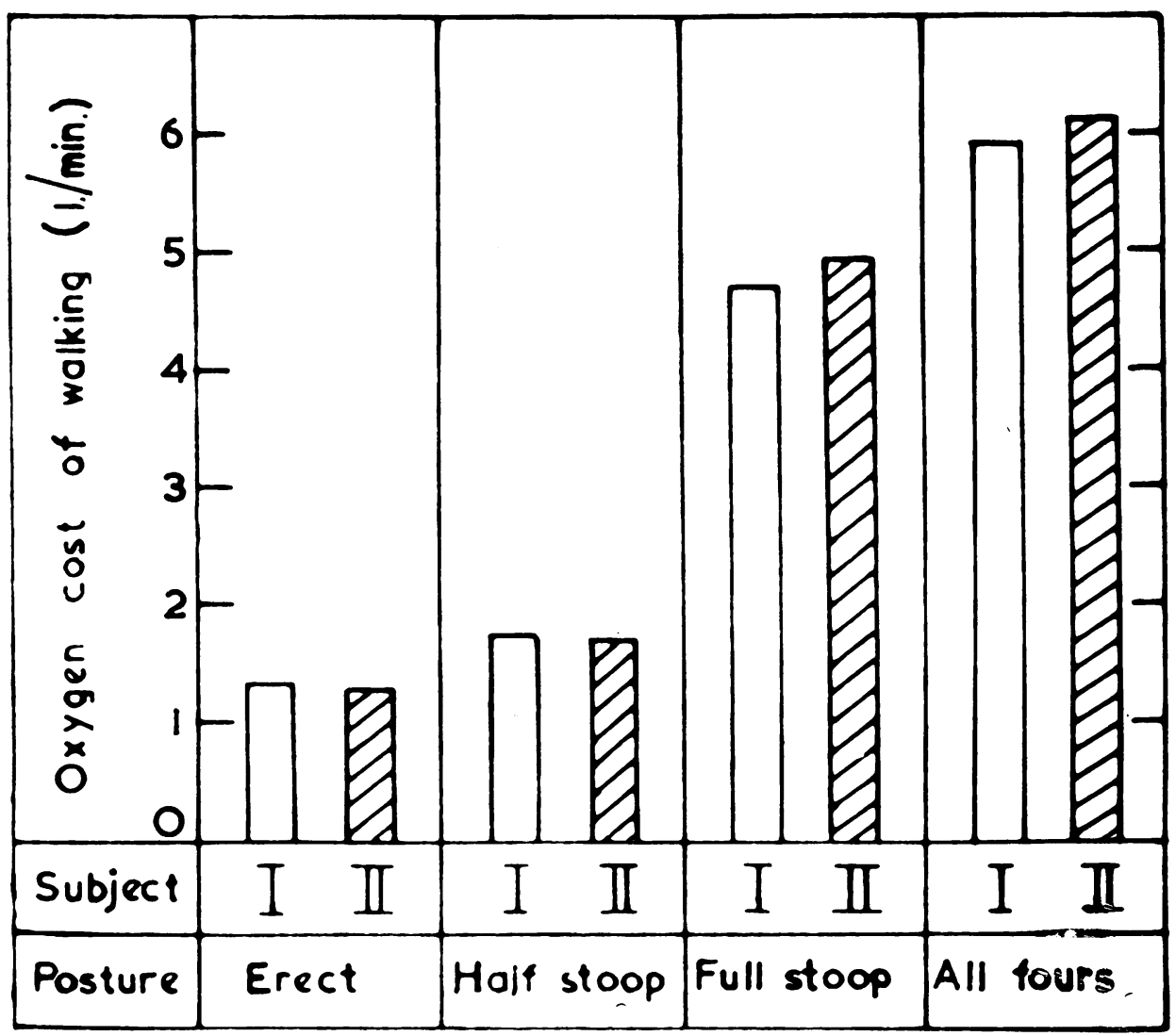

FIG. 2.-Comparison of oxygen consumption of both subjects under similar conditions.

litres was the amount absorbed during the one minute of exercise while the remainder, 3.47 litres, was the oxygen debt incurred, i.e., the excess of the oxygen intake during the period of recovery over the intake during rest (thus, $3 \times 1.012+7 \times 0.429+$ $5 \times 0.359-15 \times 0.291=3.469$ 1.). Over the short period of work the pulmonary ventilation rate was raised to nearly five and a half times the previous resting value, and it averaged five times that value during the first three minutes of recovery.

The last column of Table 2 shows that during the

TABLE 2

SUBJECT II WALKING AT $3 \frac{1}{2}$ MILES AN HOUR WITH FULL STOOP

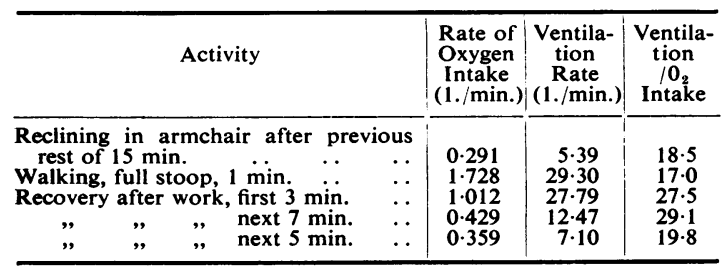

first 10 minutes immediately after walking there was considerable hyperventilation, for the ratio of the rate of lung ventilation to the rate of oxygen intake was roughly from 50 to $60 \%$ above the ratio in the period of rest before work, and the respiratory quotient was 1/14. In the light of conclusions reached by us during an earlier study of static effort (Bedford, Vernon, and Warner, 1933) we were much interested in this hyperventilation and for walking in the various postures and at the various speeds we have calculated ventilation/ oxygen-intake ratios. For the experiments in which the subject was not in a steady state while walking we have, in calculating these ratios, used the total oxygen cost of the work and a figure which we have taken to represent the total ventilation during work. It has been assumed that during the recovery period the volume of ventilation in excess of that corresponding to the ventilation rate during the pre-work period of rest was the "ventilation debt" due to exercise, and that has been added to the ventilation during exercise to obtain a figure representing the 
TABLE 3

VENTILATION RATES AND VENTILATION/OXYGEN-INTAKE RATIOS DUE TO WALKING IN VARIOUS POSTURES AT DIFFERENT SPEEDS

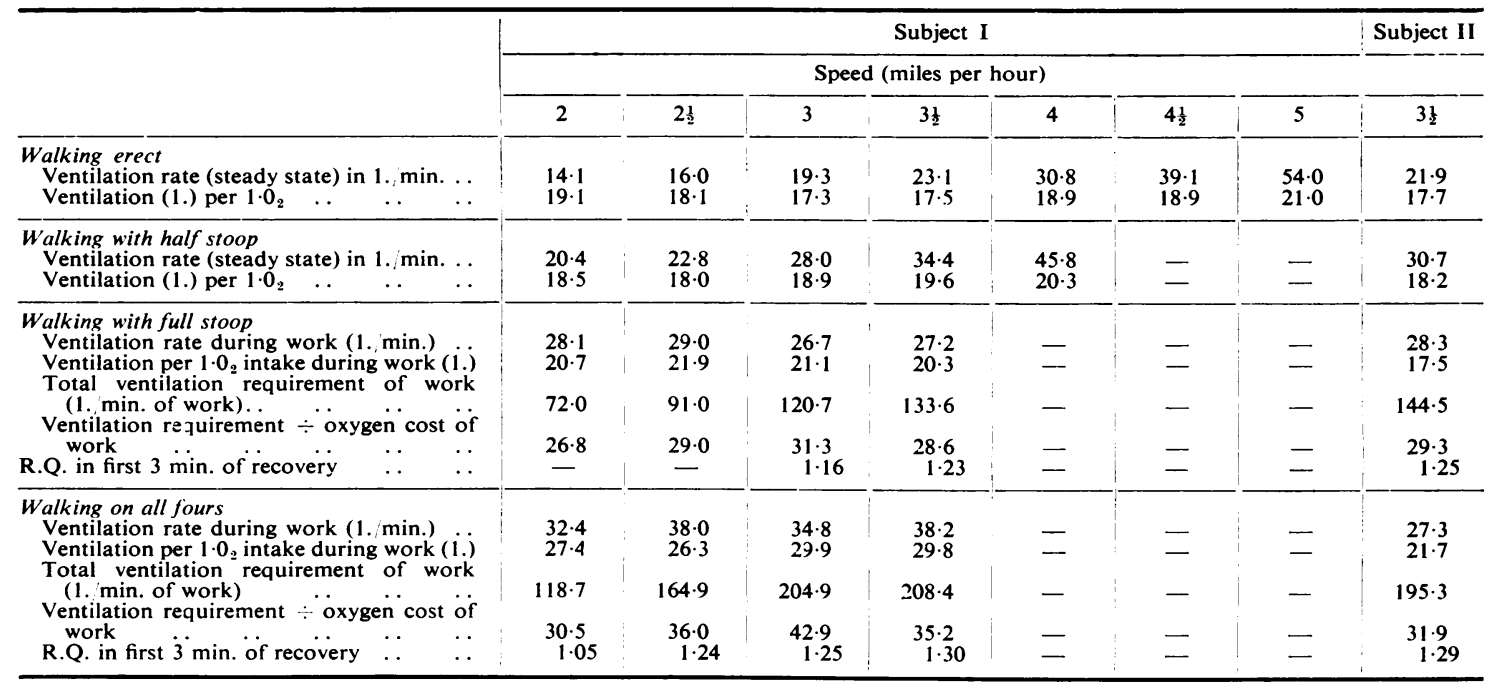

ventilation due to work. For the experiment reported in Table 2 that figure is 154.6 litres, and when it is divided by the oxygen cost of the work, $5 \cdot 2$ litres, the ratio of the ventilation requirement to the oxygen cost of the work is found to be $29 \cdot 7$.

The average ventilation rates and ventilation/ oxygen-intake ratios for both subjects are shown in Table 3, and for those experiments in the two more strenuous postures in which separate collections of expired air were made for the first three minutes of recovery the respiratory quotients during that period are also shown.

During erect and half-stoop walking at all speeds the ventilation/oxygen-intake ratios for Subject I were all below his average resting value of 22 , and the lowest values occurred at the more comfortable speeds. In the full-stoop posture, where the chest was constricted, the ventilation rate during work did not increase at the higher speeds, and the ventilation/oxygen-intake ratio, though higher than in the easier postures, remained below the average resting value. In this posture there was much hyperventilation after the exertion, as is shown by the higher ventilation/oxygen-intake ratios based on the total ventilation and oxygen requirements of the work and by the high respiratory quotients where these are available. With walking on all fours higher ventilation rates were achieved during the very short periods of work, but this exhausting effort caused yet more hyperventilation after work than occurred after walking with a full stoop. The experiments on Subject II gave results very similar to the comparable figures for Subject I.

Our rates of oxygen intake while actually walking on all fours were only about two-thirds of the average rate for Moss's miners, but much of this difference is probably attributable to differences in experimental procedure. We started that severe exercise immediately after resting for some 25 minutes, but if, as seems certain, Moss did not consider oxygen debt, it is unlikely that his subjects were rested before each determination of oxygen intake. It would then follow that in experiments lasting only one or two minutes their oxygen intake

TABLE 4

RATES OF OXYGEN INTAKE OF SUBJECT II WALKING AT $3 \$$ MILES AN HOUR COMPARED WITH RATES REPORTED BY MOSS

\begin{tabular}{|c|c|c|c|c|}
\hline \multirow[t]{2}{*}{ Time } & \multicolumn{2}{|l|}{ Subject II } & \multicolumn{2}{|c|}{$\begin{array}{c}\mathrm{O}_{2} \text { Intake }(1 . / \mathrm{min} \text {. } \\
\text { of Six of Moss's } \\
\text { Miners in Similar } \\
\text { Posture }\end{array}$} \\
\hline & Activity & $\begin{array}{c}0_{2} \\
\text { Intake } \\
(1 . / \text { min. })\end{array}$ & Mean & Range \\
\hline $12.30-$ & $\begin{array}{c}\text { Fore-period : walking erect } \\
\text { for } 1 \mathrm{~min} .\end{array}$ & - & - & \\
\hline $\begin{array}{l}12.31- \\
12.35- \\
12.37- \\
12.40- \\
12.42- \\
12.43- \\
12.46-\end{array}$ & $\begin{array}{l}\text { Walking erect, } 4 \text { min. } \\
\text { Standing, } 2 \text { min. } . . \\
\text { Walking, half stoop, } 3 \text { min. } \\
\text { Standing, } 2 \text { min. } . \\
\text { Walking, full stoop, } 1 \text { min. } \\
\text { Standing, } 3 \text { min. } . \\
\text { Walking, all fours, } 42 \text { sec. } .\end{array}$ & $\begin{array}{l}\overline{1.32} \\
\overline{1.67} \\
\overline{1.76} \\
\overline{1.99}\end{array}$ & $\begin{array}{l}\frac{1 \cdot 12}{1 \cdot 33} \\
\overline{1.92} \\
\overline{1.94}\end{array}$ & $\begin{array}{l}0.96-1 \cdot 27 \\
1 \cdot 1 \overline{7-1} \cdot 56 \\
1 \cdot 5 \overline{4-2} \cdot 35 \\
1 \cdot 59-2 \cdot 36\end{array}$ \\
\hline
\end{tabular}


would tend to be higher than if they had started exercise immediately after a long rest.

One experiment was done in which Subject II walked in each of the four postures in turn at $3 \frac{1}{2}$ miles an hour, with intervals of only two or three minutes between spells of walking. Table 4 shows the rates of oxygen intake, and for comparison the average and the maximum and minimum values reported by Moss for the six miners who completed experiments in all postures are also shown. The two miners who failed to complete the experiments in the most strenuous posture had oxygen intakes in the easier postures which were substantially higher than the maxima shown in Table 4.

In each posture Subject II's rate of oxygen intake during exercise lay within the range found by Moss in his miners, although in the erect and half-stoop postures his intakes were slightly in excess of those shown in Table 4, and in the most severe posture it differed by less than 3\% from Moss's average.

\section{Discussion}

The results which have been described show clearly the desirability of maintaining adequate headroom in mine roadways. Walking with a stoop, even when the body height is reduced by only $20 \%$, raises the energy cost of walking by between 30 and $50 \%$, and as the extent of stooping increases the cost rises rapidly. The cost of progression in what is described as the "full-stoop" posture, i.e., with a height reduction of $40 \%$, is three and a half times that of normal walking, and while it may be unusual to stoop quite so much for long distances, one frequently has to walk a considerable way stooping to an extent which probably doubles the cost of walking at a given speed. If it happens that considerable distances must be traversed while stooping in a deep and hot seam, the additional heat stress imposed by the posture may be a serious handicap.

Even at the coal face there is need for such headroom as can be given. Kommerell (1929), in a study of shovelling while in a stooping position, found that a reduction of the height from floor to ceiling from 1.2 to 1 metre caused a rise of $10 \%$ in the oxygen cost of shovelling at a given rate.

In the experiments here described we reproduced as nearly as possible the postures adopted by Moss's miners. We could have continued walking in the half-stoop posture for considerable periods without difficulty, apart from the discomfort and increasing fatigue due to postural strain, but with the full stoop we could not long continue without resting.

It is well known that during the early stages of recovery from severe exercise there is an elimination f carbon dioxide and a high respiratory quotient, and the high respiratory quotients and high ventilation/oxygen-intake ratios, apart from the high oxygen costs, that we have noted show the severity of walking with a full stoop or on all fours. These modes of progression entail considerable postural strain, and it seems possible that the high ventilation/ oxygen-intake ratios may be due to some extent to the discomfort arising from such strain. Bedford, Vernon, and Warner have earlier (1933) shown that whereas the ratio of ventilation to oxygen intake falls below the resting value during dynamic work, it increases considerably above the resting value when any static effort is sufficiently prolonged. The rise in the ratio, it was found, ran parallel with the feelings of strain associated with such effort. Pain caused such a rise in the ratio ; thus, when a painful faradaic stimulus was applied to the legs of a subject who lay resting in a reclining chair, the ventilation/ oxygen-intake ratio was raised as high as 52.6 with a respiratory quotient of $1 \cdot 37$, even though the rate of oxygen intake was only 0.49 litre per minute. The rise in the ventilation/oxygen-intake ratio which occurs in static effort was ascribed by us to the influence of painful sensations of strain.

When Moss published the results of his experiments he remarked that they showed clearly the wastage of energy that occurs when miners have to walk along low roadways, and commented that such wastage must make an appreciable difference to a man's output of work at the coal face, especially if the air temperature is high. The experiments described here show the extra cost of walking with a stoop to be much greater than Moss had found, and they therefore give added point to his comments. Walking for appreciable distances in low roadways is indeed likely to be inimical to working efficiency.

It may be possible to compute whether or not it would be economic to accept some reduction in efficiency instead of incurring costs in increasing the height of roadways, but the result of such computations cannot necessarily give the whole answer to the problem.

Discussing the responsibilities of management in industrial hygiene recently, one of us (Bedford, 1954) remarked that " methods of work, machines, and the working environment should be such as not to impose undue strain. The intelligent application of the results of physiological research can do much to ease the load on the worker and to improve his efficiency". Mining is arduous work and walking in roadways that are unnecessarily low causes undue strain, and it is therefore gratifying to note that statutory provision is now made for the improvement of mine roadways. Section 35 of the Mines and Quarries Act, 1954, requires that with certain 
exceptions every length of a road in a mine which is made after the implementation of the Act and which is used at the beginning or end of a shift by not less than 10 persons for the purpose of walking to or from their working places in the mine shall be not less than $5 \mathrm{ft}$. 6 in. high throughout. If an inspector of mines considers that any such road made before the passing of the Act should not be used unless it is heightened, he may require that it shall be increased to a height not exceeding $5 \mathrm{ft} .6 \mathrm{in}$. which he will specify.

The energetic application of these provisions should result in great improvements which are long overdue.

\section{Summary}

Experiments on two subjects are reported in which the energy cost of walking-erect, stooping, and on all fours-was measured. At a given speed, when walking with a stoop sufficient to reduce a man's height by $20 \%$, the energy cost was from 30 to $50 \%$ above that of normal walking, while walking with a stoop causing a height reduction of $40 \%$ cost three and a half times, and walking on all fours four and a quarter to five and a quarter times as much energy as normal walking.

We are indebted to Dr. R. K. Macpherson for valuable criticism.

\section{REFERENCES}

Bedford, T. (1954). British Journal of Industrial Medicine, 11, 50. Vernon, H. M., and Warner, C. G. (1933). J. Hyg., Camb., 33, 118.

Kommerell, B. (1929). Arbeitsphysiologie, 1, 278. Moss, K. N. (1935). Trans. Instn Min. Engrs, Lond., 89, 132. 